\title{
Stress-induced evolution of herbicide resistance and related pleiotropic effects
}

\section{Authors: William E. Dyer}

This is the peer reviewed version of the following article: see full citation below, which has been published in final form at https://dx.doi.org/10.1002/ps.5043. This article may be used for noncommercial purposes in accordance with Wiley Terms and Conditions for Self-Archiving.

Dyer, William Edward. "Stress-induced evolution of herbicide resistance and related pleiotropic effects." Pest Management Science 74, no. 8 (August 2018): 1759-1768. DOI:10.1002/ps.5043.

Made available through Montana State University's ScholarWorks

scholarworks.montana.edu 


\title{
Stress-induced evolution of herbicide resistance and related pleiotropic effects
}

\author{
William Edward Dyer*
}

\begin{abstract}
Herbicide-resistant weeds, especially those with resistance to multiple herbicides, represent a growing worldwide threat to agriculture and food security. Natural selection for resistant genotypes may act on standing genetic variation, or on a genetic and physiological background that is fundamentally altered because of stress responses to sublethal herbicide exposure. Stress-induced changes include DNA mutations, epigenetic alterations, transcriptional remodeling, and protein modifications, all of which can lead to herbicide resistance and a wide range of pleiotropic effects. Resistance selected in this manner is termed systemic acquired herbicide resistance, and the associated pleiotropic effects are manifested as a suite of constitutive transcriptional and post-translational changes related to biotic and abiotic stress adaptation, representing the evolutionary signature of selection. This phenotype is being investigated in two multiple herbicide-resistant populations of the hexaploid, self-pollinating weedy monocot Avena fatua that display such changes as well as constitutive reductions in certain heat shock proteins and their transcripts, which are well known as global regulators of diverse stress adaptation pathways. Herbicide-resistant populations of most weedy plant species exhibit pleiotropic effects, and their association with resistance genes presents a fertile area of investigation. This review proposes that more detailed studies of resistant $A$. fatua and other species through the lens of plant evolution under stress will inform improved resistant weed prevention and management strategies.
\end{abstract}

Keywords: herbicide resistance; non-target site resistance; plant stress response; systemic acquired herbicide resistance; weeds 
other pleiotropic effects. Plants have evolved under a wide range of biotic and abiotic stresses and in response have evolved adaptive strategies to deal with both. To combat biotic invasions by pathogenic bacteria and fungi, they have evolved highly effective innate and induced immune responses. ${ }^{5}$ The components and pathways of pattern-triggered immunity ${ }^{6}$ and systemic acquired resistance $(\mathrm{SAR})^{7}$ are well characterized, involving recognition, signal transduction, and transcriptional reprogramming in response to biotic challenge. Systemic acquired acclimation describes a constitutive upregulation of proteins that confer enhanced resistance to subsequent abiotic stresses. ${ }^{8}$ There are a number of commonalities between the two responses, $, 9,10$ including cell-surface receptors that recognize stress-related molecules, components of signal transduction cascades, and the central role of reactive oxygen species (ROS). ${ }^{11}$ Priming of pattern-triggered immunity and SAR can require multiple, consecutive exposures to modest, perhaps hormetic (see below) stresses, ${ }^{6}$ as has been noted for the evolution of NTSR. ${ }^{4,12}$ An intriguing and potentially related initiator of NTSR was recently proposed: microbial plant endophytes that either directly metabolize xenobiotics or prime host plant stress responses that include NTSR. ${ }^{13}$

When exposed to sublethal herbicide doses by improper applications or environmental constraints, susceptible plants respond in much the same as they do to other abiotic stresses (reviewed in Alberto et al. ${ }^{14}$ ). Stress resulting from abiotic sources including several herbicides ${ }^{15,16}$ induces rapid ROS generation, which in turn impacts multiple pathways and cellular components. ${ }^{4,17}$ SAR and systemic acquired acclimation are characterized by the constitutive, heritable upregulation of genes/enzymes for redox maintenance, xenobiotic metabolism, and other protective pathways, ${ }^{18,19}$ likely as a result of rapid yet persistent changes in abiotic stress-specific ${ }^{20}$ transcription factors and non-coding RNAs. ${ }^{21}$ Similarly, stress-induced changes in protein PTMs like phosphorylation and cysteine oxidation modify enzymatic and regulatory activities, allowing plants to rapidly adjust carbon flux. ${ }^{22,23}$ Plant transcriptome, proteome, and PTM changes caused by herbicide stress are quite similar to those resulting from abiotic and biotic stresses, ${ }^{24-31}$ supporting the existence of the SAHR phenotype proposed here. Although not the focus of this review, herbicide safeners also induce similar gene expression changes likely through oxylipin-mediated signaling, ${ }^{32}$ and the unclear relationship between safeners and NTSR evolution is currently under investigation. ${ }^{33,34}$ Given that systemic acquired acclimation and SAR are better understood than NTSR, this review proposes that the plant stress literature may be fertile ground for generating hypotheses about NTSR evolution and its pleiotropic effects.

The widely accepted theory for the origin of NTSR is that herbicides impose Darwinian selection on standing genetic variation in weed populations, and sublethal doses select for pre-existing individuals able to evolve resistance. ${ }^{35,36}$ Surviving individuals are thought to subsequently accumulate additional alleles for NTSR and/or MHR in succeeding generations, mostly through outcrossing. However, because the majority of the world's worst annual weeds are self-pollinating, ${ }^{37,38}$ an additional theory is proposed here that does not rely on outcrossing and incorporates a deeper understanding of the plant stress response. As discussed further below, the theory proposes that stress imposed by sublethal herbicide exposure creates a profoundly altered physiological state that provides novel sources of variation upon which selection for MHR and NTSR can act, without the need for additional alleles obtained through outcrossing.

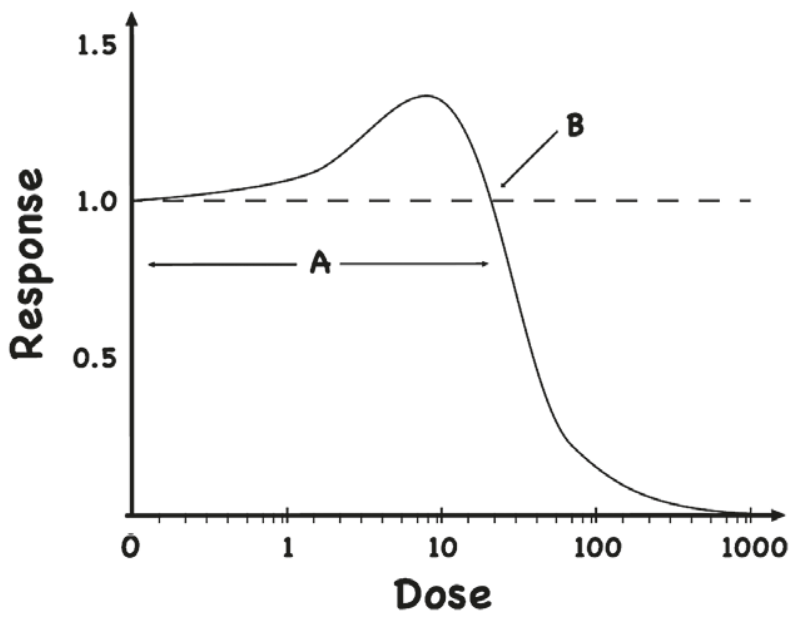

Figure 1. Theoretical herbicide dose-response graph, showing the hormetic stimulation region $(A)$ and the no observable adverse effect level (B).

Sublethal herbicide doses create a continuum of responses that have implications for resistance evolution, as illustrated by a typical dose-response curve for herbicides (or almost any inhibitor of any organism; Fig. 1). The stimulatory effect seen at very low doses of the response curve (region $\mathrm{A}$ ) is termed hormesis, a poorly understood but likely universal response. ${ }^{39}$ A recent plant study seeking a mechanistic explanation showed that hormetic doses of a disease resistance-inducing chemical enhanced Arabidopsis root growth and suppressed the expression of photosynthesis- and respiration-related genes, while higher sublethal doses induced a very different suite of defense-related transcripts. ${ }^{40}$ This finding, along with the fact that reduced herbicide applications can select for resistance in Avena fatu ${ }^{41}$ and other species ${ }^{42}$ supports the idea that hormetic and sublethal doses are part of a continuum that induces overlapping adaptive responses like NTSR. Interestingly, point B in Fig. 1 is often termed the no observable adverse effect level, although the absence of observable damage should not suggest that this dose is physiologically neutral. In fact, this dose of glyphosate induced numerous proteome changes in the fungus Aspergillus nidulans with no other observable effects. ${ }^{43}$ Hormetic herbicide doses may play a part in resistance evolution in weeds, because highly resistant and less resistant subpopulations from a heterogeneous acetyl CoA carboxylase inhibitor-resistant Alopecurus myosuroides metapopulation responded differentially to hormetic herbicide doses (Belz R, personal communication). Further, the recent widespread weed exposure to very low (perhaps hormetic) volatilized dicamba doses in the Midwestern United States may have implications for resistance evolution.

Plants exposed to (probably) hormetic doses and (certainly) higher sublethal doses of herbicides experience stress, and stress is well known to induce profound physiological changes. Stress-induced mutagenesis, ${ }^{44,45}$ originally thought to operate only in prokaryotes, is widely documented in plants in response to both biotic and abiotic stressors. Mutations are caused by rapid ROS generation, which causes random breaks in DNA ${ }^{46}$ and induces other systemic stress responses. ${ }^{15,16}$ The idea that herbicides and other pesticides can increase mutation frequencies is not new, ${ }^{47}$ although it is rarely discussed. In addition to ROS-mediated DNA damage, sublethal herbicide exposure can also lead to genetic and epigenetic changes such as gene amplification ${ }^{48}$ and altered DNA methylation patterns. ${ }^{49}$ And as 
discussed above, changes in ROS-mediated signal transduction, transcriptional remodeling, and PTM patterns create a significantly altered physiological environment during herbicide stress, with attendant widespread pleiotropic effects.

If herbicide stress is like other abiotic stresses, weeds exposed to sublethal doses unleash a vast array of heritable epigenetic, biochemical, and physiological defense/repair mechanisms, and together these changes provide novel sources of variation upon which selection for NTSR can act. As shown for systemic acquired acclimation and SAR, this variation allows selection on genome, transcriptome, and proteome changes that confer a suite of stress-response adaptations, resulting in NTSR and the SAHR phenotype. As previously proposed, ${ }^{45}$ the genetic association between stress and adaptation ${ }^{50}$ challenges widespread assumptions about the evolution of herbicide resistance. More specifically, estimates for the initial frequency of resistance alleles and constancy of mutation rates used in traditional population genetic models ${ }^{51,52}$ may be very different in a stressed plant from those of standing genetic variation, and revised values incorporated into resistance models may lead to novel and useful predictions about NTSR evolution.

\section{PLEIOTROPIC FITNESS COSTS}

Of the potential pleiotropic effects associated with resistance, fitness costs as predicted by Fisher in $1930^{53}$ have been the most studied and have shaped our expectations about herbicide resistance for decades. Under annual applications of herbicides with the same mode of action, weed populations are expected to fix resistance alleles regardless of their cost, because continued resistance is necessary for survival. However, more realistic rotations among modes of action, non-herbicide integrated weed management strategies, and other weed suppression tactics cause fluctuating selection pressure on resistance alleles with pleiotropic fitness costs. Under varying selection pressures, overall population genetic variation and cycling of allele frequencies should be maintained. ${ }^{54}$ Thus, the theoretical relationship between NTSR alleles and pleiotropic fitness cost alleles can become disassociated over time, or their effects modified through compensatory adaptation. ${ }^{55,56}$ Understanding this relationship is essential to predict the evolutionary fate of NTSR alleles.

The first well-characterized resistant weed species (Senecio vulgaris L. with target site resistance to photosystem II inhibitors ${ }^{57}$ ) fit Fisher's prediction of fitness costs exactly ${ }^{58}$ and shaped our expectations for the next 20 years. However, more recent examples from multiple disciplines show that fitness costs are not necessarily a consequence of evolved resistance to insecticides ${ }^{59}$ or fungicides, ${ }^{60}$ and the situation for herbicides remains unclear. ${ }^{61}$ In entomology, there are ongoing controversies concerning the fitness of laboratory- versus field-selected insecticide-resistant populations ${ }^{59}$ and in weed science, determining how to properly make fitness comparisons has been discussed at length. ${ }^{61,62}$ Thus, the correlation between resistance and fitness costs is not absolute, but the co-occurrence of other pleiotropic effects with resistance is consistent across many species, as shown below. For target site resistance, pleiotropic effects are likely conferred by the resistance gene, while NTSR pleiotropic effects are due to combinations of known and unknown genes.

\section{PLEIOTROPIC EFFECTS OF RESISTANCE}

Table 1 shows some known pleiotropic effects associated with herbicide resistance. For the purposes of this review, the effects are restricted to those with a non-obvious association with resistance mechanisms, are not necessarily associated with fitness costs, and are constitutively present prior to herbicide exposure. Populations with both target site and non-target site resistance are included, to illustrate that unexpected pleiotropic effects are associated with both. It should be noted here that it is unclear if the pleiotropic effect is directly conferred by resistance gene(s), or if it is associated with the action of other genes unrelated to resistance.

Whole-plant pleiotropic effects include a phenological association between seed dormancy/germination and resistance in several species. MHR A. myosuroides, Lolium rigidum, and Kochia scoparia populations had lower germination than their susceptible counterparts in certain environments. By contrast, acetolactate synthase inhibitor-resistant $K$. scoparia germinated more rapidly than susceptible counterparts at low temperatures, indicating that this association may be complex. Studies of 32 natural Ipomoea purpurea populations showed that glyphosate-resistant populations displayed lower anther-stigma distances and thus had higher rates of self-pollination than susceptible populations. Although such changes in seed germination and pollination rates would no doubt create fitness effects in all environments, negative cross-resistance of triazine-resistant populations to other herbicides would confer a fitness benefit only under ongoing herbicide selection.

At the biochemical level, triazine-resistant populations of several species display altered photosynthetic inhibition characteristics, chloroplast membrane lipid composition, and elevated heat tolerance, features that do not seem to be directly related to their well-characterized target site mutations. Paraquat resistance is associated with the monogenic upregulation of several ROS detoxification enzyme activities in Conyza bonariensis, indicating the involvement of a pleiotropic transcription factor. At the molecular level, essentially all transcriptome analyses of resistant populations show some kind of constitutive gene expression changes unrelated to biochemical resistance mechanisms. For example, several species display upregulation of SAR-associated transcripts for protein kinases and transcription factors involved in disease resistance, salicylic acid response, and others. In particular, MHR A. fatua contains a number of constitutive transcript, protein, and PTM changes related to the stress response, as discussed below. This phenotype may be more common than currently recognized, because most transcriptome and proteome surveys to date have focused on known mechanisms of resistance, to the exclusion of other possibilities. Pleiotropic effects of genes conferring resistance to fungicides ${ }^{83}$ and insecticides ${ }^{84}$ are well documented, and so their presence in herbicide-resistant populations should not be surprising.

Resistance conferred by amplification of the gene encoding the herbicide target enzyme deserves extra attention, due to the high potential for pleiotropic effects. Detailed investigations of glyphosate-resistant Amaranthus palmeri populations reveal that resistant plants possess multiple copies of a 297-kb cassette containing one copy of the 5-enol-pyruvylshikimate 3-phosphate synthase gene and 72 additional open reading frames. ${ }^{48}$ The amplified cassette shows little homology to sequences from glyphosate-sensitive A. palmeri plants, indicating that it is a recent evolutionary event and was not present before glyphosate use. Among the additional predicted cassette genes are those similar to stress response genes, while others are involved in transposon mobility and DNA replication. (Molin W, and Saski $C$, personal communication). If shown to be functional, the potential for pleiotropic effects of these additional genes is 


\begin{tabular}{|c|c|c|c|c|}
\hline Species & Resistance & Target $(\mathrm{T})$ or non-target $(\mathrm{N})$ & Pleiotropic effects & Reference \\
\hline \multicolumn{5}{|l|}{ Whole plant effects } \\
\hline Lolium rigidum & MHR & Both & Altered seed germination & 63 \\
\hline Alopecurus myosuroides & ALS inhibitors & $\mathrm{T}$ & Altered seed germination patterns & 64 \\
\hline Kochia scoparia & Glyphosate & $\mathrm{T}$ & Reduced seed longevity and germination & 65 \\
\hline Kochia scoparia & ALS inhibitors & $?$ & Faster germination at low temperatures & 66 \\
\hline Ipomea purpurea & Glyphosate & $?$ & Reduced anther-stigma distance & 67 \\
\hline E. crus-galli; C. canadensis & Triazines & $\mathrm{T}$ & Negative herbicide cross-resistance & 68 \\
\hline \multicolumn{5}{|l|}{ Biochemical effects } \\
\hline S. vulgaris; C. album & Atrazine & $\mathrm{T}$ & Altered chloroplast lipids & 69 \\
\hline Glycine max (cell culture) & Atrazine & $\mathrm{T}$ & Altered chloroplast lipids; heat tolerance & 70 \\
\hline Brassicanapus & Atrazine & $\mathrm{T}$ & Increased sensitivity to photoinhibition & 71 \\
\hline Brassica campestris & Triazines & $\mathrm{T}$ & Increased chlorophyll $a / b$ complex & 72 \\
\hline Conyza bonariensis & Paraquat & $\mathrm{N}$ & Increased ROS detoxification enzymes & 73 \\
\hline Kochia scoparia & Dicamba & $?$ & Increased chalcone synthase expression & 74 \\
\hline Eleusine indica & Glyphosate & $\mathrm{T}$ & Phosphofructokinase gene amplification & 75 \\
\hline Amaranthus palmeri & Glyphosate & $\mathrm{T}$ & Numerous co-amplified predicted genes & 48 \\
\hline \multirow[t]{2}{*}{ Alopecurus myosuroides } & ALS inhibitors & $\mathrm{N}$ & Disease resistance and peroxidases & 76 \\
\hline & & & Altered flavonoid metabolism & 77 \\
\hline Alopecurus aequalis & Mesosulfuron & $\mathrm{N}$ & Salicylic acid-responsive kinases & 78 \\
\hline \multirow{2}{*}{ Avena fatua } & MHR & $\mathrm{N}$ & Numerous differential genes & 28 \\
\hline & & & Altered protein and PTM profiles & 79 \\
\hline Lolium rigidum & MHR & $\mathrm{N}$ & Overexpressed protein kinases & 26 \\
\hline Ambrosia trifida & Glyphosate & $?$ & Altered pathogen response transcripts & 31 \\
\hline Eleusine indica & Paraquat & $?$ & Numerous differentially expressed genes & 80 \\
\hline Echinochloa crus-galli & Quinclorac & $?$ & Photosynthetic and defense proteins & 81 \\
\hline Cicer arietinum & Imazethapyr & $?$ & Transcription factors; core metabolism & 82 \\
\hline
\end{tabular}

substantial. In the related species Amaranthus tuberculatus, an extra ring chromosome containing amplified copies of the 5-enol-pyruvylshikimate 3-phosphate synthase gene appears to be the result of stress-induced chromosomal alterations. ${ }^{85}$ Further detailed investigations of gene amplification mechanisms and pleiotropic effects in these and other resistant species will no doubt lead to important insights into NTSR evolution.

Although not yet documented in resistant populations, herbicide-induced epigenetic effects have been confirmed, first by low-resolution techniques showing evidence for glyphosate-induced $^{86}$ and atrazine-induced ${ }^{87}$ alterations in DNA methylation patterns. More recently, detailed investigations of Arabidopsis plants treated with sublethal glyphosate doses showed that methylation changes were not uniformly spread across the genome, but many were clustered in differentially methylated regions associated with transposons, and the majority were related more specifically to glyphosate injury than to other abiotic and biotic stresses, suggesting a level of precision in DNA methylation response. ${ }^{49}$ Current research will determine if transposons are in fact activated by these changes, and if their activation is associated with pleiotropic effects as seen elsewhere ${ }^{88}$ (Westwood J, personal communication).

\section{MULTIPLE HERBICIDE RESISTANT AVENA FATUA}

We recently described the MHR3 and MHR4 populations of $A$. fatua that are resistant to members of all selective (in small grains) herbicide families available in North America for A. fatua control. ${ }^{89,90}$ Specifically they are resistant to the acetyl-CoA carboxylase inhibitors fenoxaprop-P-ethyl, tralkoxydim, and pinoxaden, the acetolactate synthase inhibitors imazamethabenz-methyl and flucarbazone, the growth inhibitor difenzoquat, the photosystem I inhibitor paraquat (MHR3 only), and the very long chain fatty acid biosynthesis inhibitors triallate and prosulfocarb, with resistant/susceptible ratios ranging from 1.4 to 57 . MHR plants do not contain known target site mutations for acetyl-CoA carboxylase or acetolactate synthase inhibitors, and the cytochrome P450 monooxygenase inhibitor malathion partially reversed the resistance phenotype for a subset of herbicides, indicating the involvement of P450-mediated NTSR mechanisms. ${ }^{90}$ Resistance to flucarbazone, imazamethabenz-methyl, and pinoxaden is controlled by three separate but linked nuclear genes. ${ }^{91}$ Although all the specific biochemical mechanisms conferring NTSR to this wide array of herbicides are not yet known, resistance to fenoxaprop-P-ethyl and imazamethabenz-methyl may be due to reduced rates of carboxylesterase activity, an enzymatic step necessary for cellular uptake and conversion of these pre-herbicides into active inhibitors. ${ }^{92}$ Enhanced herbicide catabolism does not appear to play a major role in MHR A. fatua, because glutathione $S$-transferase specific activities towards fenoxaprop-P-ethyl and imazamethabenz-methyl were not different between untreated MHR and susceptible plants ${ }^{34}$ and only a relatively small number of constitutively elevated xenobiotic catabolism transcripts and proteins were detected in MHR plants. ${ }^{28,34}$ The A. fatua NTSR phenotype is heritable and stable for multiple generations in the absence of herbicide treatment. ${ }^{90}$ Specific herbicide use histories from the fields where the MHR A. fatua populations were collected are not available, but regional practices indicate that they evolved under 40 years of chronological rotations of selective herbicides. ${ }^{90}$ 
Additional insights into MHR A. fatua evolution may be gleaned from comparison with the previously characterized FG93R22 A. fatua population derived from the same location as MHR with resistance to only triallate and difenzoquat. ${ }^{93}$ Resistant/susceptible ratios to these two herbicides are similar in MHR and FG93R22, suggesting commonalities in resistance mechanisms. Triallate resistance in FG93R22 is conferred by reduced rates of sulfoxidase activity, ${ }^{93,94}$ a pre-herbicide activation step required for toxicity, and is controlled by two recessive nuclear genes..$^{95}$ Difenzoquat resistance is associated with herbicide efflux from the cytoplasm and irreversible binding to cell wall components. ${ }^{96}$ Although it is not known if MHR plants have the same mechanisms as FG93R22, it is tempting to speculate that the constitutive elevation of xenobiotic transporter transcripts in MHR plants ${ }^{28}$ is related to difenzoquat resistance.

Potential fitness costs associated with the MHR A. fatua phenotype are unclear. Under non-competitive conditions in the greenhouse, photosynthetic and relative growth rates were not different between susceptible and MHR plants, but MHR plants produced fewer tillers and seeds than susceptible plants. ${ }^{89}$ However, a second greenhouse study showed that there were no differences in competitive abilities between susceptible and MHR plants under gradients of biotic (competition with Triticum aestivum) and abiotic (limiting nitrogen) stresses. ${ }^{97}$ Fitness comparisons have not been conducted under field conditions.

\section{PLEIOTROPIC FEATURES IN RESISTANT WEEDS}

As shown in Table 1, all resistant populations characterized to date exhibit various pleiotropic effects at the whole plant, biochemical, or molecular level. Of these, MHR A. fatua contains more documented molecular changes than other species, as well as several unusual resistance mechanisms, and so it has been used as a model to investigate the primary stress effects associated with the evolution of NTSR. ${ }^{28,34}$ Initial efforts to describe these have focused on constitutive differences between MHR and susceptible populations, because they are most likely to represent changes that would lead to pleiotropic effects. Transcriptome and proteome analyses showed that MHR plants have constitutively higher levels of transcripts and proteins with functions in stress response, disease resistance, redox maintenance, xenobiotic transport and catabolism, transcriptional regulation, and signal transduction. ${ }^{28}$ For example, transcripts for three protein kinases including the lectin S-receptor-like serine/threonine-protein kinase LecRK2, a well-characterized SAR receptor/signal transducer, were constitutively elevated in MHR4 plants. By contrast, levels of heat shock protein (HSP) transcripts and proteins were constitutively lower than in susceptible plants..$^{28}$ In the first phosphoproteome and redox proteome comparisons between resistant and susceptible plants of any species, PTMs of proteins with functions in core cellular processes were shown to be constitutively reduced in MHR A. fatua plants, perhaps in association with certain fitness costs. ${ }^{79}$ PTMs of proteins involved in xenobiotic and stress response, ROS detoxification/redox maintenance, heat shock response, and intracellular signaling were more abundant in MHR than susceptible plants. Overall, this suite of constitutive changes in MHR A. fatua populations could represent pleiotropic effects of NTSR, or it is more likely that they are an evolutionary signature of ongoing stress responses like systemic acquired acclimation or SAR, of which NTSR is only one aspect.

\section{NTSR: A ROLE FOR HEAT SHOCK PROTEINS?}

Of all the changes associated with MHR A. fatua discussed above, perhaps the most intriguing is the constitutive reduction of HSP transcripts and proteins ${ }^{28}$ and altered HSP PTM patterns. ${ }^{92}$ In all eukaryotes, HSPs are typically induced and subjected to PTMs in response to heat shock as well as a wide variety of biotic and abiotic stresses, ${ }^{98}$ and they are implicated in hormetically induced epigenetic effects on phenotype. ${ }^{99}$ HSPs primarily function as molecular chaperones that repair misfolded client proteins during stress, although a subset regulate transcription factors for a diverse set of genes. ${ }^{100}$ For example, several HSPs are involved in adaptation of the yeast Saccharomyces cerevisiae to the auxinic herbicide 2,4-D. ${ }^{101}$ In the same species ${ }^{102}$ and related fungi, ${ }^{103}$ the Ssa1p HSP70 binds to and represses the Pdr3p transcription factor controlling expression of an ATP-binding cassette transporter that confers multiple drug resistance. Thus, a reduced level of Ssa1p derepresses transporter expression and leads to enhanced resistance in fungi. In MHR A. fatua, constitutively reduced HSP transcripts and proteins, and elevated xenobiotic transporter transcripts ${ }^{28}$ may indicate the presence of an orthologous regulatory system in higher plants that contributes to herbicide resistance.

Constitutively reduced HSP profiles have also been reported in stress-tolerant plant biotypes. For example, a comparison of natural Chenopodium album biotypes showed that those adapted to stressful environments contained lower levels of certain HSPs than those from moderate habitats, both constitutively and in response to thermal stress. ${ }^{104}$ Comparable ecological studies of Drosophila ${ }^{105}$ and Arabidopsis ${ }^{106}$ reported similar findings, suggesting that this is an evolutionarily conserved strategy for stress acclimation. In a series of papers starting in 1998, it was proposed that HSP90 functions as a global regulator for stress adaptation by acting as a capacitor for phenotypic variation. ${ }^{107,108}$ Under stress, HSP90 levels are typically induced but under some conditions cannot keep pace with demands for client protein re-folding and repair of regulatory pathway components. Limiting HSP90 levels thus allows normally buffered polymorphisms to persist, providing novel sources of variation upon which selection can act, and the polymorphisms that are adaptive in the new stressed environment become fixed. Experimental evidence shows that pharmacologic reductions of HSP90 levels in Drosophila ${ }^{108}$ and Arabidopsis ${ }^{107}$ produced a wide variety of novel phenotypes, and the same treatment in S. cerevisiae and Candida albicans led to the evolution of resistance to two classes of fungicides. ${ }^{109,110}$ The role of HSP90 as a global regulator of diverse stress-induced signaling pathways is now well accepted. ${ }^{98}$ The results from MHR A. fatua plants indicate that a very different stress, i.e. sublethal herbicide damage, may have caused them to evolve a similar strategy during herbicide selection, leading to a heritable downregulation of certain HSPs and the consequent evolution of NTSR.

It is important to point out that the phenotype just described is much more complex than the acute induction of HSPs in response to a single stress event, which is well documented in eukaryotes. ${ }^{98}$ However, neither acute HSP induction nor the constitutive HSP reductions seen in MHR A. fatua have been investigated in resistant populations of other species. It is hoped that other transcriptome and proteome datasets will be re-examined for these and other constitutive changes that may inform a better understanding of NTSR evolution. Similarly, it will be of interest to determine whether herbicide-resistant populations are also more tolerant to 
other biotic and abiotic stresses, as is well documented for systemic acquired acclimation and SAR. For example, a coral (Acropora formosa) population adapted to a polluted environment was more tolerant to glyphosate and elevated temperature than one from a pristine environment. ${ }^{111}$ For MHR A. fatua, research is underway to determine levels of resistance to other abiotic and biotic stresses.

\section{IS MHR AVENA FATUA AN OUTLIER OR HARBINGER?}

As noted above, the number and variety of constitutive transcript and protein alterations in MHR A. fatua appears to be larger (or better documented) than in other resistant populations. Also, $A$. fatua and the MHR phenotype have several characteristics that are not typical of other species. First, unlike L. rigidum, A. myosuroides, and $A$. tuberculatus, $A$. fatua is a predominantly self-pollinating species with limited seed dispersal and substantial levels of seed dormancy, ${ }^{112}$ features that tend to delay the appearance and spread of novel traits. Second, A. fatua is an allohexaploid, in contrast to the diploid species just mentioned. Polyploidy provides additional standing genetic variation upon which selection can act, but at the same time may buffer novel resistance mutations through expression of homoeologous sensitive alleles, slowing HR evolution. ${ }^{113}$ Third, more than 40 years of annual herbicide applications were required before the MHR populations became noticeable, ${ }^{90}$ a considerably longer time frame than is typical. Thus, the MHR A. fatua phenotype may be an outlier when compared with other species.

However, the environment, herbicide spectrum, and chronology of herbicide use that selected for MHR A. fatua populations are not unusual, and so other species in similar circumstances may be following a parallel evolutionary path. Certainly, MHR is not unusual, since its incidence is rapidly increasing worldwide especially in monocots. ${ }^{114}$ MHR populations of self-pollinating polyploid species in weedy genera like Eleusine and Echinochloa have been reported, and if these traits contribute to a delay in NTSR evolution as argued here for $A$. fatua, additional resistant populations may continue to appear. Further, transcriptome and proteome surveys of many HR and MHR populations of other species have also detected SAR-like constitutive alterations, ${ }^{24,26}$ as is shown here for MHR A. fatua. By far the largest category of elevated transcripts before and after herbicide treatment of NTSR Apera spica-venti populations was for nucleotide binding site-leucine-rich repeat proteins, ${ }^{115}$ a large family of receptors involved in SAR to plant diseases. ${ }^{116}$ Although it is possible that such constitutive changes are unrelated to NTSR, it seems more likely that both they and NTSR are part of a general stress response. The commonality of such changes among resistant populations of many species indicates that the MHR A. fatua phenotype may indeed be a harbinger of additional, similar cases in the future.

Figure 2 shows a proposed model for some of the key cellular players in recognition, uptake, signal transduction, and subsequent induced responses to sublethal herbicide doses. Actively absorbed herbicides ${ }^{117}$ are transported by membrane-bound receptors, of which (except for auxinic herbicides ${ }^{118}$ ) very little is known. If they are similar to receptor-like kinases involved in systemic acquired acclimation and SAR, an HSP90-mediated signal transduction cascade is activated, leading to transcriptional remodeling, PTMs, and possibly epigenetic events. These changes in turn lead to the SAHR phenotype through translation or modification of stress-related proteins with functions in defense, repair, ROS management, xenobiotic inactivation, and likely NTSR. This

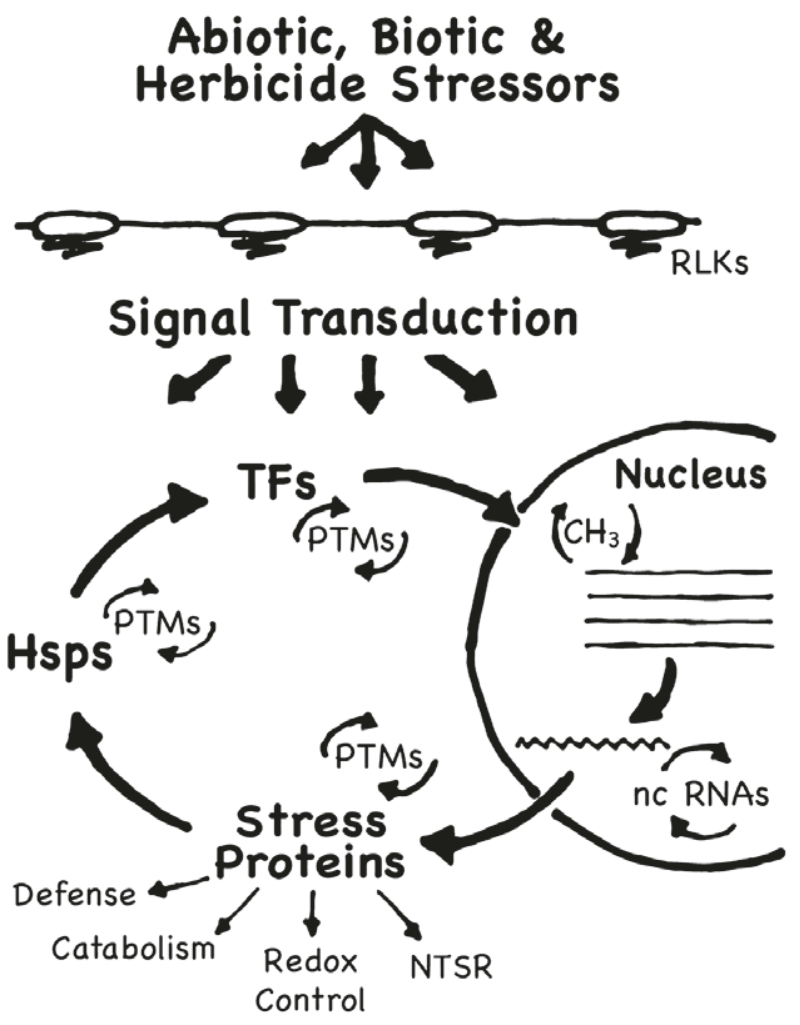

Figure 2. A model for sublethal herbicide-induced stress and plant responses. Actively absorbed herbicides are transported by cell-surface receptors, which may be similar to receptor-like kinases involved in systemic acquired acclimation and systemic acquired resistance (SAR) that activate a heat shock protein 90 (HSP90)-mediated signal transduction cascade, leading to transcriptional remodeling, post-translational modifications (PTMs), and possibly epigenetic events. These changes in turn cause translation or modification of stress-related proteins with functions in defense, repair, reactive oxygen species (ROS) management, xenobiotic inactivation, and likely non-target site resistance (NTSR). RLKs, receptor-like kinases; $\mathrm{CH}_{3}$, DNA methylation; nc RNAs, non-coding RNAs; TFs, transcription factors.

review proposes that an experimental focus on the components of these processes will provide valuable insights into NTSR evolution. Much has been learned about SAR and other plant stress responses by characterizing their receptors, the ensuing signal transduction, and induced effects.

\section{FINDING AND STUDYING NASCENT NTSR POPULATIONS}

Valuable insights into NTSR and its evolution can be obtained by changing the way that we sample for resistance. Because most if not all field-selected NTSR populations originated from producer complaints of herbicide non-performance, it is likely that the university or company researchers visiting these fields collected only the most robust and therefore most resistant plants/seeds for further study, and the barely surviving weeds under the crop canopy (survivors) were ignored. However, these survivors may have been in the early stages of NTSR evolution, and a conscious effort to sample and study them could provide valuable information. For example, survivor and robust NTSR populations of the same species could be compared to distinguish between two possible chronologies of NTSR evolution. In the traditionally accepted evolutionary chronology, herbicides initially select for direct NTSR 
mechanisms such as enhanced metabolism or transport. ${ }^{36}$ However, high fitness costs correlated with these alleles limit population sizes of survivors, so their appearance is usually overlooked. Over time, additional stress responses evolve that compensate for the initial fitness deficits, allowing populations to recover, prosper, and be noticed by producers. The genetic basis of this chronology for fungicide resistance in Aspergillus nidulans was recently described. ${ }^{119}$ If this is also true for herbicide selection, then theory predicts that survivor populations would display high fitness costs, $^{53}$ while costs would have been purged or compensated for in robust populations. At the molecular level, constitutive changes in survivor populations would include the downregulation of transcripts/proteins with housekeeping functions related to fitness.

A second possible chronology of NTSR evolution is more aligned with the scenario proposed in this review: general stress responses are first induced by sublethal herbicide doses, and these can simultaneously include both NTSR and any number of pleiotropic effects. If pleiotropic fitness costs are high, limited population growth may eventually be ameliorated through outcrossing and/or compensatory adaptation. However, if fitness costs are moderate, NTSR populations will rapidly predominate under continuing herbicide use. In this scenario, both survivor and robust populations would be expected to display SAR-related constitutive changes in transcripts and proteins, as is seen for the species listed in Table 1 and the MHR A. fatua populations described here.

Obtaining evidence for these two possible chronologies of NTSR evolution may be difficult, but both will add to our basic knowledge about plant responses to stress and will also inform improved resistant weed management strategies. If pleiotropic effects are related to primary stress effects as argued above, then a better characterization of pleiotropy in well-characterized NTSR populations of $L$. rigidum, A. myosuroides, and species with strong genetic/genomic resources will be informative. Further, because it is established that low-dose impacts cannot be predicted from high dose experiments, ${ }^{120}$ further research on the role of initial sublethal herbicide effects on NTSR evolution is clearly warranted.

\section{CONCLUSION}

This review proposes that, in addition to the evolution of herbicide resistance through selection on standing genetic variation, it also evolves in response to stress induced by sublethal herbicide exposure. In the latter case, NTSR appears to be only one of many possible stress-induced responses, and together, these responses can lead to the SAHR phenotype and a number of unpredictable pleiotropic effects. This view is supported by phenological changes associated with resistance, and by transcriptome and proteome surveys showing that current resistant populations exhibit a number of constitutive alterations apparently unrelated to NTSR mechanisms. If designed correctly, such surveys generate vast amounts of unbiased data, and then the subsequent challenge often centers on deciding which differences between resistant and susceptible populations to verify and pursue. In the NTSR surveys published to date, this choice was based on previous knowledge about established herbicide resistance mechanisms like enhanced metabolism, and so the results reinforce what is already known. A more informative approach is proposed here that includes a focus on candidates for the primary regulators and physiological markers of stress, with the idea that such features can provide deep insights into the fundamental mechanisms of NTSR evolution and its pleiotropic effects. Resistance due to gene amplification can also present unique opportunities, by providing a window into the potential pleiotropic effects of genomic rearrangements and additional genes that are co-amplified along with herbicide target site genes. The co-occurrence of plants with both target site resistance and NTSR in the same population indicates that current definitions of these terms may be unnecessarily restrictive from a research standpoint ${ }^{121}$ and this author believes that a shifted focus on the primary stress effects of sublethal herbicide exposure will inform both types of resistance. And finally, as both the appearance of NTSR populations and the worldwide occurrence of environmental stress are expected to increase, expanded research on NTSR evolution and its potential for pleiotropic effects should be a high priority.

\section{ACKNOWLEDGEMENTS}

Sincere appreciation is extended to Jonny Gressel for the invitation to write this review, to René Feyereisen, William Molin, Regina Belz, and James Westwood for discussion and sharing unpublished work, to Tyler Maxwell and Katie Steward for graphics, and to seven anonymous reviewers for their constructive comments. Work in the author's laboratory is supported by USDA-NIFA-AFRI grant 2016-2067 013-24 888, US EPA Strategic Agricultural Initiative grant X8-97873401-0, Bayer CropScience, the Montana Noxious Weed Trust Fund, the Montana Wheat and Barley Committee, and the Montana Agricultural Experiment Station.

\section{REFERENCES}

1 Heap I, Global perspective of herbicide-resistant weeds. Pest Manage Sci 70:1306-1315 (2014).

2 Pimentel D, Lach L, Zuniga R and Morrison D, Environmental and economic costs of nonindigenous species in the United States. Bioscience 50:53-65 (2000).

3 Ghanizadeh $\mathrm{H}$ and Harrington $\mathrm{KC}$, Non-target site mechanisms of resistance to herbicides. Crit Rev Plant Sci 36:1 - 11 (2017).

4 Delye C, Unravelling the genetic bases of non-target-site-based resistance (NTSR) to herbicides: a major challenge for weed science in the forthcoming decade. Pest Manage Sci 69:176-187 (2013).

5 Dodds PN and Rathjen JP, Plant immunity: towards an integrated view of plant-pathogen interactions. Nat Rev Genet 11:539-548 (2010).

6 Boller $\mathrm{T}$ and Felix G, A renaissance of elicitors: perception of microbe-associated molecular patterns and danger signals by pattern-recognition receptors. Annu Rev Plant Biol 60:379-406 (2009).

7 Fu ZQ and Dong X, Systemic acquired resistance: turning local infection into global defense. Annu Rev Plant Biol 64:839-863 (2013).

8 Suzuki N, Miller G, Salazar C, Mondal HA, Shulaev E, Cortes DF et al., Temporal-spatial interaction between reactive oxygen species and abscisic acid regulates rapid systemic acclimation in plants. Plant Cell 25:3553-3569 (2013).

9 Atkinson NJ and Urwin PE, The interaction of plant biotic and abiotic stresses: from genes to the field. J Exp Bot 63:3523-3543 (2012).

10 Fujita M, Fujita Y, Noutoshi Y, Takahashi F, Narusaka Y, Yamaguchi-Shinozaki $\mathrm{K}$ et al., Crosstalk between abiotic and biotic stress responses: a current view from the points of convergence in the stress signaling networks. Curr Opin Plant Biol 9:436-442 (2006).

11 Mittler $R$ and Blumwald $E$, The roles of ROS and ABA in systemic acquired acclimation. Plant Cell 27:64-70 (2015).

12 Neve $P$ and Powles $S$, Recurrent selection with reduced herbicide rates results in the rapid evolution of herbicide resistance in Lolium rigidum. Theor Appl Genet 110:1154-1166 (2005).

13 Tétard-Jones $\mathrm{C}$ and Edwards $\mathrm{R}$, Potential roles for microbial endophytes in herbicide tolerance in plants. Pest Manage Sci 72:203-209 (2016).

14 Alberto D, Serra A-A, Sulmon C, Gouesbet G and Couée I, Herbicide-related signaling in plants reveals novel insights for herbicide use strategies, environmental risk assessment and global 
change assessment challenges. Sci Total Environ 569:1618-1628 (2016).

15 Dayan FE and Watson SB, Plant cell membrane as a marker for light-dependent and light-independent herbicide mechanisms of action. Pestic Biochem Physiol 101:182-190 (2011).

16 Sewelam N, Kazan K and Schenk PM, Global plant stress signaling: reactive oxygen species at the cross-road. Front Plant Sci 7:187 (2016). https://doi.org/10.3389/fpls.2016.00187.

17 Suzuki N, Rivero RM, Shulaev V, Blumwald E and Mittler R, Abiotic and biotic stress combinations. New Phytol 203:32-43 (2014).

18 Parween T, Jan S, Mahmooduzzafar S, Fatma T and Siddiqui ZH, Selective effect of pesticides on plant - a review. Crit Rev Food SCi Nutr 56:160-179 (2016).

19 Serra A-A, Couée I, Heijnen D, Michon-Coudouel S, Sulmon C and Gouesbet G, Genome-wide transcriptional profiling and metabolic analysis uncover multiple molecular responses of the grass species lolium perenne under low-intensity xenobiotic stress. Front Plant $\mathrm{SCi}$ 6:1124 (2015). https://doi.org/10.3389/fpls.2015.01124.

20 Nakashima K, Yamaguchi-Shinozaki K and Shinozaki K, The transcriptional regulatory network in the drought response and its crosstalk in abiotic stress responses including drought, cold, and heat. Front Plant Sci 5:1 - 7 (2014). https://doi.org/10.3389/fpls.2014.00170.

21 Shriram V, Kumar V, Devarumath RM, Khare TS and Wani SH, MicroRNAs as potential targets for abiotic stress tolerance in plants. Front Plant Sci 7:817 (2016). https://doi.org/10.3389/fpls.2016.00817.

22 Dietz K-J, Redox regulation of transcription factors in plant stress acclimation and development. Antioxid Redox Signal 21:1356-1372 (2014).

23 Waszczak C, Akter S, Jacques S, Huang J, Messens J and Van Breusegem F, Oxidative post-translational modifications of cysteine residues in plant signal transduction. J Exp Bot 66:2923-2934 (2015).

24 Das M, Reichman JR, Haberer G, Welzl G, Aceituno FF, Mader MT et al., A composite transcriptional signature differentiates responses towards closely related herbicides in Arabidopsis thaliana and Brassica napus. Plant Mol Biol 72:545-556 (2010).

25 Unver T, Bakar M, Shearman RC and Budak H, Genome-wide profiling and analysis of Festuca arundinacea miRNAs and transcriptomes in response to foliar glyphosate application. Mol Genet Genomics 283:397-413 (2010).

26 Gaines TA, Lorentz L, Figge A, Herrmann J, Maiwald F, Ott MC et al., RNA-seq transcriptome analysis to identify genes involved in metabolism-based diclofop resistance in Lolium rigidum. Plant $J$ 78:865-876 (2014)

27 Hofer $M$, Felsenstein $F$ and Petersen $M$, Molecular analysis of metabolic resistance in blackgrass. Julius-Kühn-Archiv 443:73-80 (2014).

28 Keith BK, Burns EE, Bothner B, Carey CC, Mazurie AJ, Hilmer JK et al., Intensive herbicide use has selected for constitutively elevated levels of stress-responsive mRNAs and proteins in multiple herbicide-resistant Avena fatua L. Pest Manage Sci 73:2267-2281 (2017).

29 Peng Y, Comparative illumina RNA-seq and tonoplast proteomic approach to study glyphosate resistant mechanisms in Conyza canadensis biotypes, in Plant and Animal Genome XXII Conference. (2014).

30 Dong S and Adams KL, Differential contributions to the transcriptome of duplicated genes in response to abiotic stresses in natural and synthetic polyploids. New Phytol 190:1045-1057 (2011).

31 Padmanabhan KR, Segobye K, Weller SC, Schulz B and Gribskov M, Preliminary investigation of glyphosate resistance mechanism in giant ragweed using transcriptome analysis. F1000Research 5:1354 (2016). https://doi.org/10.12688/f1000research.8932.1.

32 Riechers $\mathrm{DE}$, Kreuz $\mathrm{K}$ and Zhang $\mathrm{Q}$, Detoxification without intoxication: Herbicide safeners activate plant defense gene expression. Plant Physiol 153:3-13 (2010).

33 Duhoux A, Pernin F, Desserre D and Délye C, Herbicide safeners decrease sensitivity to herbicides inhibiting acetolactate-synthase and likely activate non-target-site-based resistance pathways in the major grass weed Lolium sp. (rye-grass). Front Plant Sci 8:1310 (2017). https://doi.org/10.3389/fpls.2017.01310.

34 Burns EE, Keith BK, Refai MY, Bothner B and Dyer WE, Proteomic and biochemical assays of glutathione-related proteins in susceptible and multiple herbicide resistant Avena fatua L. Pestic Biochem Physiol 140:69-78 (2017).
35 Gressel J and HM LB, Herbicide Resistance in Plants. Wiley, Hoboken, NJ, USA (1982).

36 Délye $C$, Jasieniuk $M$ and Le Corre $V$, Deciphering the evolution of herbicide resistance in weeds. Trends Genet 29:649-658 (2013).

37 Snell R and Aarssen LW, Life history traits in selfing versus outcrossing annuals: exploring the 'time-limitation' hypothesis for the fitness benefit of self-pollination. BMC Ecol 5:2 (2005).

38 Holm G, Phicknett D, Pancho J and Herberger J, The World's Worst Weeds. University Press, Honolulu, Hawaii (1977).

39 Belz RG and Duke SO, Herbicide-mediated hormesis, in Pesticide Dose: Effects on the Environment and Target and Non-target Organisms, ed. by Duke SO, Kudsk P and Solomon KR. ACS Publications, pp. 135-148 (2017).

40 Rodriguez-Salus $M$, Bektas $Y$, Schroeder $M$, Knoth C, Vu T, Roberts $\mathrm{P}$ et al., The synthetic elicitor 2-(5-bromo-2-hydroxyphenyl)-thiazolidine-4-carboxylic acid links plant immunity to hormesis. Plant Physiol 170:444-458 (2016).

41 Busi R, Girotto M and Powles SB, Response to low-dose herbicide selection in self-pollinated Avena fatua. Pest Manage Sci 72:603-608 (2016).

42 Busi R, Neve P and Powles S, Evolved polygenic herbicide resistance in Lolium rigidum by low-dose herbicide selection within standing genetic variation. Evol Appl 6:231-242 (2012).

43 Poirier F, Boursier C, Mesnage R, Oestreicher N, Nicolas V and Vélot C, Proteomic analysis of the soil filamentous fungus Aspergillus nidulans exposed to a roundup formulation at a dose causing no macroscopic effect: a functional study. Environ Sci Pollut Res 24:25933-25946 (2017).

44 Fitzgerald DM, Hastings P and Rosenberg SM, Stress-induced mutagenesis: implications in cancer and drug resistance. Ann Rev Cancer Biol 1:119-140 (2017).

45 Gressel J and Levy AA, Stress, mutators, mutations and stress resistance, in Abiotic Stress Adaptation in Plants, ed. Pareek A, Sopory SK, Bohnert HJ and Govindjee. Springer, Dordrecht, The Netherlands, pp. 471-483 (2009).

$46 \mathrm{Hu}$ Z, Cools T and De Veylder L, Mechanisms used by plants to cope with DNA damage. Annu Rev Plant Biol 67:439-462 (2016).

47 Gressel J, Low pesticide rates may hasten the evolution of resistance by increasing mutation frequencies. Pest Manage Sci 67:253-257 (2011).

48 Molin WT, Wright AA, Lawton-Rauh A and Saski CA, The unique genomic landscape surrounding the EPSPS gene in glyphosate resistant Amaranthus palmeri: a repetitive path to resistance. BMC Genomics 18:91 (2017).

49 Kim G, Clarke CR, Larose H, Tran HT, Haak DC, Zhang L et al., Herbicide injury induces DNA methylome alterations in Arabidopsis. Peer $J$ 5:e3560 (2017).

50 Ram $Y$ and Hadany L, Stress-induced mutagenesis and complex adaptation. Proc R Soc Lond, Ser B: Biol Sci 281:20141025 (2014).

51 Renton M, Busi R, Neve P, Thornby D and Vila-Aiub M, Herbicide resistance modelling: past, present and future. Pest Manag Sci 70:1394-1404 (2014).

52 Liu C, Bridges ME, Kaundun SS, Glasgow L, Owen MD and Neve P, A generalised individual-based algorithm for modelling the evolution of quantitative herbicide resistance in arable weed populations. Pest Manag Sci 73:462-474 (2017).

53 Fisher RA, The Genetical Theory of Natural Selection: A Complete Variorum Edition. Oxford University Press, Oxford, UK (1999).

54 Mitchell-Olds T, Willis JH and Goldstein DB, Which evolutionary processes influence natural genetic variation for phenotypic traits? Nat Rev Genet 8:845-856 (2007).

55 Chari S, Marier C, Porter C, Northrop E, Belinky A and Dworkin I, Compensatory evolution via cryptic genetic variation: distinct trajectories to phenotypic and fitness recovery. bioRxiv https://doi .org/10.1101/200725 (2017).

56 Pavlicev $\mathrm{M}$ and Wagner GP, A model of developmental evolution: selection, pleiotropy and compensation. Trends Ecol Evol 27:316-322 (2012).

57 Ryan G, Resistance of common groundsel to simazine and atrazine. Weed Sci 18:614-616 (1970).

58 Conard S and Radosevich S, Ecological fitness of Senecio vulgaris and Amaranthus retroflexus biotypes susceptible or resistant to atrazine. $J$ Appl Ecol 16:171-177 (1979).

59 ffrench-Constant $\mathrm{RH}$ and Bass C, Does resistance really carry a fitness cost? Curr Opin Insect Sci 21:39-46 (2017). 
60 Lucas JA, Hawkins NJ and Fraaije BA, The evolution of fungicide resistance, in Advances in Applied Microbiology. Elsevier, Amsterdam, Netherlands, pp. 29-92 (2015).

61 Cousens RD and Fournier-Level A, Herbicide resistance costs: what are we actually measuring and why? Pest Manag Sci (2017). https://doi .org/10.1002/ps.4819.

62 Vila-Aiub MM, Neve P and Roux F, A unified approach to the estimation and interpretation of resistance costs in plants. Heredity 107:386-394 (2011).

63 Vila-Aiub M, Neve P, Steadman K and Powles S, Ecological fitness of a multiple herbicide-resistant Lolium rigidum population: dynamics of seed germination and seedling emergence of resistant and susceptible phenotypes. J Appl Ecol 42:288-298 (2005).

64 Délye C, Menchari Y, Michel S, Cadet É and Le Corre V, A new insight into arable weed adaptive evolution: mutations endowing herbicide resistance also affect germination dynamics and seedling emergence. Ann Bot 111:681-691 (2013).

65 Osipitan OA and Dille JA, Fitness outcomes related to glyphosate resistance in kochia (Kochia scoparia): what life history stage to examine? Front Plant Sci 8:1090 (2017).

66 Dyer WE, Chee PW and Fay PK, Rapid germination of sulfonylurearesistant Kochia scoparia L. accessions is associated with elevated seed levels of branched chain amino acids. Weed Sci 41:18-22 (1993).

67 Kuester A, Fall E, Chang SM and Baucom RS, Shifts in outcrossing rates and changes to floral traits are associated with the evolution of herbicide resistance in the common morning glory. Ecol Lett 20:41-49 (2017).

68 Gadamski G, Ciarka D, Gressel J and Gawronski SW, Negative cross-resistance in triazine-resistant biotypes of Echinochloa crus-galli and Conyza canadensis. Weed Sci 48:176-180 (2000).

69 Pillai P and John JBS, Lipid composition of chloroplast membranes from weed biotypes differentially sensitive to triazine herbicides. Plant Physiol 68:585-587 (1981).

70 Alfonso $M$, Yruela I, Almárcegui $S$, Torrado $E$, Pérez $M A$ and Picorel R, Unusual tolerance to high temperatures in a new herbicide-resistant d1 mutant from Glycine max (L.) Merr. cell cultures deficient in fatty acid desaturation. Planta 212:573-582 (2001).

71 Sundby C, Chow WS and Anderson JM, Effects on photosystem II function, photoinhibition, and plant performance of the spontaneous mutation of serine-264 in the photosystem II reaction center D1 protein in triazine-resistant Brassica napus L. Plant Physiol 103:105-113 (1993).

72 Burke JJ, Wilson RF and Swafford JR, Characterization of chloroplasts isolated from triazine-susceptible and triazine-resistant biotypes of Brassica campestris L. Plant Physiol 70:24-29 (1982).

73 Shaaltiel Y, Chua N-H, Gepstein S and Gressel J, Dominant pleiotropy controls enzymes co-segregating with paraquat resistance in Conyza bonariensis. Theor Appl Genet 75:850-856 (1988).

74 Pettinga DJ, Ou J, Patterson EL, Jugulam M, Westra P and Gaines TA, Increased chalcone synthase (chs) expression is associated with dicamba resistance in Kochia scoparia. Pest Manag Sci (2017). https://doi.org/10.1002/ps.4778.

75 Chen J, Huang $H$, Wei S, Huang Z, Wang $X$ and Zhang C, Investigating the mechanisms of glyphosate resistance in goosegrass (Eleusine indica (L.) Gaertn.) by RNA sequencing technology. Plant $J$ 89:407-415 (2017).

76 Gardin JAC, Gouzy J, Carrère S and Délye C, Alomybase, a resource to investigate non-target-site-based resistance to herbicides inhibiting acetolactate-synthase (ALS) in the major grass weed Alopecurus myosuroides (black-grass). BMC Genomics 16:590 (2015).

77 Cummins I, Wortley DJ, Sabbadin F, He Z, Coxon CR, Straker HE et al., Key role for a glutathione transferase in multiple-herbicide resistance in grass weeds. Proc Natl Acad Sci USA 110:5812-5817 (2013).

78 Zhao N, Li W, Bai S, Guo W, Yuan G, Wang F et al., Transcriptome profiling to identify genes involved in mesosulfuron-methyl resistance in Alopecurus aequalis. Front Plant Sci 8:1391 (2017). https://doi.org/ 10.3389/fpls.2017.01391.

79 Burns EE, Keith BK, Refai MY, Bothner B and Dyer WE, Constitutive redox and phosphoproteome changes in multiple herbicide resistant Avena fatua $\mathrm{L}$ are similar to those of systemic acquired resistance and systemic acquired acclimation. J Plant Physiol 220:105-114 (2018).
80 An J, Shen X, Ma Q, Yang C, Liu S and Chen Y, Transcriptome profiling to discover putative genes associated with paraquat resistance in goosegrass (Eleusine indica L.). PloS one 9:e99940 (2014).

81 Yang X, Zhang Z, Gu T, Dong M, Peng Q, Bai L et al., Quantitative proteomics reveals ecological fitness cost of multi-herbicide resistant barnyardgrass (Echinochloa crus-galli L.). J Proteomics 150:160-169 (2017).

82 Iquebal MA, Soren KR, Gangwar P, Shanmugavadivel P, Aravind K, Singla $D$ et al., Discovery of putative herbicide resistance genes and its regulatory network in chickpea using transcriptome sequencing. Front Plant Sci 8:958 (2017). https://doi.org/10.3389/fpls.2017 .00958 .

83 Elad Y, Shabi E and Katan T, Negative cross resistance between benzimidazole and $n$-phenylcarbamate fungicides and control of Botrytis cinerea on grapes. Plant Pathol 37:141-147 (1988).

84 Sparks TC, Dripps JE, Watson GB and Paroonagian D, Resistance and cross-resistance to the spinosyns-a review and analysis. Pestic Biochem Physiol 102:1 -10 (2012).

85 Koo D-H, Jugulam M, Putta K, Cuvaca IB, Peterson D, Currie RS et al., Gene duplication and aneuploidy trigger rapid evolution of herbicide resistance in common waterhemp. Plant Physiol 176:1932-1938 (2018). https://doi.org/10.1104/pp.17.01668.

86 Nardemir G, Agar G, Arslan E and Erturk FA, Determination of genetic and epigenetic effects of glyphosate on Triticum aestivum with RAPD and CRED-RA techniques. Theor Exp Plant Physio/ 27:131 - 139 (2015).

87 Lu YC, Feng SJ, Zhang JJ, Luo F, Zhang S and Yang H, Genome-wide identification of DNA methylation provides insights into the association of gene expression in rice exposed to pesticide atrazine. Sci Rep 6:1-15 (2016). https://doi.org/10.1038/srep18985.

88 Ashapkin V, Kutueva L and Vanyushin B, Epigenetic variability in plants: heritability, adaptability, evolutionary significance. Russ J Plant Physiol 63:181-192 (2016).

89 Lehnhoff EA, Keith BK, Dyer WE, Peterson RK and Menalled F, Multiple herbicide resistance in wild oat and impacts on physiology, germinability, and seed production. Agron J 105:854-862 (2013).

90 Keith B, Lehnhoff E, Burns E, Menalled F and Dyer W, Characterisation of Avena fatua populations with resistance to multiple herbicides. Weed Res 55:621-630 (2015).

91 Burns E, Keith B, Talbert $L$ and Dyer W, Non-target site resistance to flucarbazone, imazamethabenz and pinoxaden is controlled by three linked genes in Avena fatua. Weed Res 58:8-16 (2017).

92 Burns EE, Genetic and physiological characterization and ecological management of non-target site resistance in multiple herbicide resistant Avena fatua L. PhD dissertation, Montana State University (2017).

93 Kern AJ, Colliver CT, Maxwell BD, Fay PK and Dyer WE, Characterization of wild oat (Avena fatua L.) populations and an inbred line with multiple herbicide resistance. Weed Sci 44:847-852 (1996).

94 Kern AJ, Peterson DM, Miller EK, Colliver CC and Dyer WE, Triallate resistance in Avena fatua L. is due to reduced herbicide activation. Pestic Biochem Physiol 56:163-173 (1996).

95 Kern A, Myers T, Jasieniuk M, Murray B, Maxwell B and Dyer W, Two recessive gene inheritance for triallate resistance in Avena fatua $\mathrm{L}$. $J$ Hered 93:48-50 (2002).

96 Kern AJ and Dyer WE, Compartmental analysis of herbicide efflux in susceptible and difenzoquat-resistant Avena fatua L. suspension cells. Pestic Biochem Physiol 61:27-37 (1998).

97 Lehnhoff EA, Keith BK, Dyer WE and Menalled FD, Impact of biotic and abiotic stresses on the competitive ability of multiple herbicide resistant wild oat (Avena fatua). PloS one 8:5 (2013). https://doi.org/ 10.1371/journal.pone.0064478.

98 Jacob P, Hirt $\mathrm{H}$ and Bendahmane A, The heat shock protein/chaperone network and multiple stress resistance. Plant Biotechnol J 15:405-414 (2017).

99 Costantini D, Early-life hormesis and oxidative experiences fine-tune the adult phenotype, in Oxidative Stress and Hormesis in Evolutionary Ecology and Physiology. Springer-Verlag Berlin Heidelberg, pp. 39-74 (2014).

100 Morimoto RI, Dynamic remodeling of transcription complexes by molecular chaperones. Cell 110:281-284 (2002).

101 Simoes T, Teixeira M, Fernandes A and Sá-Correia I, Adaptation of Saccharomyces cerevisiae to the herbicide 2, 4-dichlorophenoxyacetic acid, mediated by msn2p-and msn4p-regulated genes: important role of spi1. Appl Environ Microbiol 69:4019-4028 (2003). 
102 Shahi P, Gulshan K and Moye-Rowley WS, Negative transcriptional regulation of multidrug resistance gene expression by an HSP70 protein. J Biol Chem 282:26822-26831 (2007).

103 Paul S and Moye-Rowley WS, Multidrug resistance in fungi: regulation of transporter-encoding gene expression. Front Physiol 5:143 (2014).

104 Barua D, Heckathorn SA and Coleman JS, Variation in heat-shock proteins and photosynthetic thermotolerance among natural populations of Chenopodium album L. from contrasting thermal environments: implications for plant responses to global warming. J Integr Plant Biol 50:1440-1451 (2008).

105 Sørensen J, Dahlgaard J and Loeschcke V, Genetic variation in thermal tolerance among natural populations of Drosophila buzzatii: down regulation of HSP70 expression and variation in heat stress resistance traits. Funct Ecol 15:289-296 (2001).

106 Zhang N, Vierling E and Tonsor S, Adaptive divergence in transcriptome response to heat and acclimation in Arabidopsis thaliana plants from contrasting climates. bioRxiv https://doi.org/10.1101/ 044446 (2016).

107 Queitsch C, Sangster TA and Lindquist S, Hsp90 as a capacitor of phenotypic variation. Nature 417:618-624 (2002).

108 Rutherford SL and Lindquist S, Hsp90 as a capacitor for morphological evolution. Nature 396:336-342 (1998).

109 Cowen LE and Lindquist S, Hsp90 potentiates the rapid evolution of new traits: drug resistance in diverse fungi. Science 309:2185-2189 (2005).

110 Cowen LE, Hsp90 orchestrates stress response signaling governing fungal drug resistance. PLoS Path 5:e1000471 (2009).

111 Amid C, Olstedt M, Gunnarsson JS, Le Lan H, Tran Thi Minh H, Van den Brink PJ et al., Additive effects of the herbicide glyphosate and elevated temperature on the branched coral Acropora formosa in Nha Trang, Vietnam. Environ Sci Pollut Res (2017). https://doi.org/10 .1007/s11356-016-8320-7.
112 Dyer WE, Exploiting weed seed dormancy and germination requirements through agronomic practices. Weed Sci 43:498-503 (1995).

113 Yu O, Ahmad-Hamdani M, Han H, Christoffers M and Powles S, Herbicide resistance-endowing accase gene mutations in hexaploid wild oat (Avena fatua): insights into resistance evolution in a hexaploid species. Heredity 110:220-231 (2013).

114 Heap I, The international survey of herbicide resistant weeds. Available http://www.weedscience.org [8 February 2018].

115 Babineau M, Microevolution of ALS inhibitor herbicide resistance in loose silky bentgrass (Apera spica-venti). PhD dissertation, Aarhus Universitet, Institut for Agroøkologi (2017).

116 French E, Kim B-S and Iyer-Pascuzzi AS, Mechanisms of quantitative disease resistance in plants, in . Seminars in Cell and Developmental Biology. Elsevier, Amsterdam, Netherlands, pp. 201-208 (2016).

117 Sterling TM, Mechanisms of herbicide absorption across plant membranes and accumulation in plant cells. Weed Sci 42:263-276 (1994).

118 Prigge MJ, Greenham K, Zhang Y, Santner A, Castillejo C, Mutka AM et al., The Arabidopsis auxin receptor $\mathrm{f}$-box proteins afb4 and afb5 are required for response to the synthetic auxin picloram. G3: Genes, Genomes Genetics 6:1383-1390 (2016).

119 Dettman JR, Rodrigue N, Schoustra SE and Kassen R, Genomics of compensatory adaptation in experimental populations of Aspergillus nidulans. G3: Genes, Genomes Genetics 7:427-436 (2017).

120 Welshons WV, Thayer KA, Judy BM, Taylor JA, Curran EM and Vom Saal FS, Large effects from small exposures. I. Mechanisms for endocrine-disrupting chemicals with estrogenic activity. Environ Health Perspect 111:994-1006 (2003).

121 Gressel J, Perspective: consider removing 'inherited' from definitions of pesticide resistance. Outlooks Pest Manag 26:220-222 (2015). 